\title{
Physical properties of gluten-free bread caused by water addition
}

\author{
Renata Różyło ${ }^{1 *}$, Dariusz Dziki², Urszula Gawlik-Dziki ${ }^{3}$,Grażyna Cacak-Pietrzak ${ }^{4}$, Antoni Miśs, \\ and Stanisław Rudy ${ }^{2}$
}

\author{
${ }^{1}$ Department of Equipment Operation and Maintenance in the Food Industry, University of Life Sciences, Doświadczalna 44, \\ 20-280 Lublin, Poland \\ ${ }^{2}$ Thermal Engineering Department, University of Life Sciences, Doświadczalna 44, 20- 280, Lublin, Poland \\ ${ }^{3}$ Department of Biochemistry and Food Chemistry, University of Life Sciences, Skromna 8, 20-704 Lublin, Poland \\ ${ }^{4}$ Division of Cereal Technology, Faculty of Food Sciences, Warsaw University of Life Sciences, Nowoursynowska 159C, \\ 02-786 Warsaw, Poland \\ ${ }^{5}$ Institute of Agrophysics, Polish Academy of Sciences, Doświadczalna 4, 20-290 Lublin, Poland
}

Received November 13, 2014; accepted May 11, 2015

\begin{abstract}
A b s t r a c t. In this paper, we propose for the first time a description (regression and canonical form) of the changes in the physical properties of several types of natural gluten-free bread produced with different amounts of water in the recipe. Five types of bread, made of corn flour (100\%), rice flour (100\%), corn and rice flour (50:50\%), buckwheat, corn, and rice flour (30:35:35\%), were investigated. It has been noticed that, by changing the amount of water addition to the dough, it is possible to significantly affect the quality of different types of natural gluten-free bread. Addition of water from 80 to $120 \%$ of flour mass, resulted in significant changes in the quality of bread. Bread made of corn flour required the largest amount of water addition (120\%); however, bread made of rice flour was characterized by a better quality with the lowest amount of water addition ( $80 \%$ ), while bread made of corn and rice flour and buckwheat, corn, and rice flour were characterized by the best quality when the amount of water addition was $90 \%$. Changes in the physical properties of bread were described as second degree polynomial regression equations or by linear regression and the canonical form was proposed.

K e y w o r d s: gluten-free bread, water, equations
\end{abstract}

\section{INTRODUCTION}

The market for gluten-free products is very promising and recent scientific studies have increasingly focused on these products (de la Hera et al., 2013; Różyło et al., 2015 a,b,c; Ziobro et al., 2013). Gluten-free bread is not fully accepted by consumers (Mariotti et al., 2013); therefore, a number of studies have addressed the impact of various additives on the quality of gluten-free bread. In recent stu-

*Corresponding author e-mail: renata.rozylo@up.lublin.pl dies, gluten-free bread was supplemented with guar gum, xanthan (Gambuś et al., 2007; Sabanis and Tzia, 2011), pectin (Gambuś et al., 2007; Ziobro et al., 2013), kappa-carrageenan (Sabanis and Tzia, 2011), carboxymethylcellulose (Sciarini et al., 2012), hydroxypropylmethylcellulose (de la Hera et al., 2013; Nishita et al., 1975; Sabanis and Tzia, 2011), and inulin (Ziobro et al., 2013).

In the studies presented by McCarthy et al. (2005) and Gómez et al. (2013), gluten-free bread prepared with different water additions was supplemented with hydroxypropylmethylcellulose. The combination of hydrocolloids (pectin, sodium carboxymethylcellulose, agarose, xanthan, and oat $\beta$-glucan) with two levels of water was studied by Lazaridou et al. (2007). The effect of water, albumen, and fat on the quality of gluten-free bread containing amaranth flour was studied by Schoenlechner et al. (2010). Hager and Arendt (2013) showed the influence of hydroxypropylmethylcellulose (HPMC), xanthan gum, and their combination with water addition. In this study the gluten-free bread was produced with a limited extent (10\% increase) of water addition. De la Hera et al. (2013) and Gómez et al. (2013) used two different amounts of water addition in the preparation of gluten-free bread supplemented with hydroxypropylmethylcellulose.

Most previous work focuses on improving the properties of gluten-free bread with a variety of recipes and also technological additives. Currently, many consumers are

(C) 2015 Institute of Agrophysics, Polish Academy of Sciences 
looking for natural products only based on flour, yeast, and water. There is a lack of studies comparing the quality of natural gluten-free bread made from dough of different capacities. In addition, there is no description of the changes in the physical properties of bread caused by a wide range of added water.

In our study, we have proposed for the first time a description (regression and canonical form) of the changes in the physical properties of several types of natural glutenfree bread produced with different amounts of water. The bread recipe was only based on gluten-free flour, salt, and yeast. Water addition was in the range of 80 to $120 \%$ (flour weight basis) in the recipe. Four kinds of natural glutenfree bread formulation: corn flour (CR) $(100 \%)$, rice flour (RF) $(100 \%)$, corn and rice flour (CRF) $(50: 50 \%)$, and buckwheat, corn, and rice flour (BCRF) (30:35:35\%) were studied in comparison with the commercial gluten-free bread concentrate.

\section{MATERIAL AND METHODS}

The raw material for making gluten-free bread included three types of flour and one commercial concentrate of gluten-free flour as a control. The corn, rice, and buckwheat flour was commercial flour sourced from Glutenex (PL). The corn flour was characterised by a protein content of $5.9 \%$, a carbohydrate content of $78 \%$, an ash content of $0.45 \%$, and a fat content of $3.0 \%$. The rice flour was characterised by a protein content of $7.2 \%$, a carbohydrate content of $79.2 \%$, an ash content of $0.22 \%$, and a fat content of $0.7 \%$. The buckwheat flour was characterized by a protein content of $12.6 \%$, a carbohydrate content of $69.3 \%$, an ash content of $2.3 \%$, and a fat content of $3.1 \%$. The gluten-free flour concentrate was also provided by Glutenex (Sady near Poznań, Poland) and, according to the manufacturer declaration, consisted of corn starch, wheat starch, corn flour, glucose, sugar, salt, bamboo fibre, guar gum, pectin, and mono and diglycerides of fatty acids. The gluten-free bread concentrate was characterized by a protein content of $0.7 \%$, a carbohydrate content of $83.3 \%$, and a fat content of $0.2 \%$. The protein content was evaluated according to ISO 20483:2006 (Kjeldahl method), the ash content according to ISO 2171:2007, and the fat content according to ISO 11085:2008. Total carbohydrates were calculated as a difference between the protein, fat, ash and moisture contents in flour.

The dried instant yeasts (Instaferm) were obtained from Lallemand Iberia, SA, Portugal. Salt was purchased from a local market.

Samples of bread dough were prepared using the straight dough method. This method is also commonly used for wheat bread preparation. Bread was baked in a laboratory oven equipped with a fermentation chamber (Sadkiewicz Instruments, PL). The five bread formulations used in this study were based on: $\mathrm{CF}-100 \%$; RF-100\%; CRF - 50:50\%, buckwheat, BCRF - 30:35:35\%, and the commercial glutenfree bread concentrate (CC) as a control. The corn and rice flour was used in the formulations as the most popular and available gluten-free flour. The addition of buckwheat flour at the $30 \%$ level was chosen from a pool of previous studies (Sakac et al., 2011; Wronkowska and Soral-Śmietana, 2008). In addition to flour, salt (2\%), yeast (in an amount equivalent to $3 \%$ of compressed yeasts), and water were used in the formulation (according to baking practice - the amount of flour is given as $100 \%$ and the ratio of the other components are converted to the weight of flour). Water was used in five different concentrations varying from 80 to $120 \%$ of the flour basis. The temperature of the added water was $30^{\circ} \mathrm{C}$. The dough was prepared after mixing all the ingredients in a 5 -speed mixer (Kitchen Aid, St. Joseph, MI, USA) for $5 \mathrm{~min}$. After mixing, the dough was weighed, divided, and formed into loaves of equal mass $(300 \mathrm{~g})$, and then subjected to proofing performed at $35^{\circ} \mathrm{C}$ and $75-88 \%$ RH for $40 \mathrm{~min}$.

The loaves were baked at $230^{\circ} \mathrm{C}$ for $25-35 \mathrm{~min}$ in a laboratory oven (live steam was injected immediately after the loaves were placed in the oven) (Sadkiewicz Instruments, Bydgoszcz, Poland). Baking tests were performed on six loaves (in triplicate on two loaves). Next, the baked loaves were wrapped in polyethylene bags and stored at room temperature $\left(21^{\circ} \mathrm{C}\right)$.

The weight and volume of the bread baked were determined one day after baking. The bread loaf volume was measured using the millet seed displacement method (Jakubczyk and Haber, 1983) and the bread loaf volume of $100 \mathrm{~g}$ of bread was calculated.

Crumb whiteness was estimated using a type MB whiteness meter (Sadkiewicz Instruments, Bydgoszcz, Poland). Measurement with the instrument is made with the use of a monochromatic light source with a wavelength of $1=565 \mathrm{~nm}$, while quantitative analysis of reflected light, after conversion to an electric signal, takes place in a microprocessor system. Bread crumb whiteness measurements were made in 6 replicates, analysing 2 central slices from each loaf.

Digital analysis of the crumb was performed (MultiScan Base v 14.02 programme) based on determination of the percentage of pore area on $3 \times 3 \mathrm{~cm}$ scanned crumb (hp Scanjet 3570c) slices. These measurements were made on an area derived from the central part of the crumb and the measurements of the percentage area of crumb pores were performed as described previously (Różyło et al., 2015b).

The textural properties of the bread crumb were tested both one and three days after baking. The measurements were performed with the aid of a ZWICK Z020/TN2S strength tester. The loaves were sliced mechanically. The slices were cut from the middle part of the loaf (without

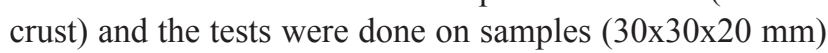
(central region of the bread slice) in 12 replicates. In this study, the samples were compressed using a capital 
equipped with a $30 \mathrm{~mm}$ plug until a $50 \%$ depth at a crosshead speed of $1 \mathrm{~mm} \mathrm{~s}^{-1}$ was achieved (Różyło, 2014a,b). The samples were compressed twice (curves 1 and 2) to give a two-bite TPA (Gámbaro et al., 2006), from which textural parameters were obtained: hardness (peak force 1 ), elasticity (length of the base of the area 2 ), cohesiveness (area 2 /area 1), and chewiness (hardness $\times$ elasticity $\times$ cohesiveness).

To assess the changes caused by storage $\left(B S_{\mathrm{d}}-\right.$ degree of staling bread), the percentage changes in hardness were calculated (Różyło, 2014a; Różyło et al., 2014) as follows.

$$
B S_{d}=\frac{H_{3 d}-H_{1 d}}{H_{1 d}} 100 \%
$$

where: $H_{3 d}, H_{1 d}$ - bread crumb hardness estimated after 3 days and 1 day of storage, respectively.

The assessment of bread crumb texture heterogeneity $\left(T H_{i}\right)$ (Różyło, 2013) was performed on the basis of the measurement of variations in the entire profile of a bread crumb slice in 6 replicates:

$$
T H_{i}=\frac{S}{H} 100 \%,
$$

$S$-standard deviation of bread crumb hardness, $H$ - mean value from the results of bread crumb hardness.

For sensory evaluation, the samples were sliced mechanically. Bread slices, divided into four parts, were presented $(1 \mathrm{~cm}$ thick) on plastic dishes coded and served in randomized order (Matos and Rosell, 2012). The panel for the sensory evaluation consisted of 52 untrained consumers (21-50 years old, 30 females and 22 males) who were habitual consumers of bread and who evaluated the bread overall acceptability.

According to a nine-point hedonic scale (1: dislike extremely, 5: neither like nor dislike, 9: like extremely), the hedonic test was used to determine the taste, texture, appearance of loaf, and overall acceptability of different types of bread based on the degree of liking or disliking (Lim et al., 2011). Aromatic, smooth, type-specific features receive the highest scores for taste. Approximate type-specific features obtain an intermediate score, and the worst score is given to bread characterized by inappropriate taste and smell; for example, bitter, stale, or bland. Evaluation of crumb texture was based on the determination of its softness and flexibility. The soft and flexible crumb obtains most points, soft but non-flexible crumb obtains intermediate scores, and the worst scores are allocated to hard, brittle crumb. The evaluation of the external appearance of loaf, such as volume and shape, was based on the assessment of whether bread has risen appropriately with a regular shape or insufficiently with an irregular shape. In general, all distinguishing features were taken into account in the overall evaluation.
Statistical analysis was conducted at a significance level of $\alpha=0.05$ using Statistica by Statsoft. Measurement scores were subjected to analysis of variance (ANOVA). When significant differences in ANOVA were detected, the means were compared using the Tukey Range test. The regression equations were also evaluated and in cases where the equation was a second degree polynomial equation, we transformed it into a canonical form of the equation. The canonical form of the equation allows calculation of the coordinates of the parabola vertex.

The typical form of the second-degree polynomial equation is as follows:

$$
f(x)=\mathrm{a} x^{2}+\mathrm{b} x+\mathrm{c},
$$

where: $\mathrm{a} \neq 0$, and $\mathrm{a}, \mathrm{b}, \mathrm{c}$ are numeric constants.

The canonical form of equation is as follows:

$$
f(x)=\mathrm{a}(x-\mathrm{p})^{2}+\mathrm{q},
$$

where: $\mathrm{p}=-\frac{\mathrm{b}}{2 \mathrm{a}}, \mathrm{q}=-\frac{\Delta}{4 \mathrm{a}}, \Delta=\mathrm{b}^{2}-4 \mathrm{ac}$.

The constants $p$ and $q$ are the coordinates of the parabola vertex $V=(\mathrm{p}, \mathrm{q})$, which allows easy reading of where the function reaches its maximum or minimum value.

\section{RESULTS AND DISCUSSION}

Analysis of the results showed that the overall appearance (Fig. 1) of the gluten-free breads was significantly dependent on the recipe composition, as well as on dough efficiency (the amount of water addition). This figure presents the effect of the water content on the physical appearance of gluten-free bread. In general, breads collapsed when too much water was added. The commercial flour mix (CC) (starch with several additives) accepted a wide variation in the water content $(80-110 \%)$, contrary to the rice flour, which absorbed very little water (80, not 90\%). The corn flour (CF) accepted $120 \%$ water content but an $80 \%$ share of water in the dough yielded unsatisfactory, almost non-porous bread.

The mixtures of the corn and rice flour (CRF) gave intermediate results, showing that corn flour had some 'buffering' effect, hence, this flour type was very beneficial to the appearance of gluten-free bread prepared with a very lean formulation (no additives).

The results of the changes in the quality (Fig. 2a-f) of the different types of gluten-free breads were described by quadratic regression or linear regression equations (Table 1). In the literature, there is a lack of such descriptions for gluten-free bread. In previous studies relating only to wheat bread, regression equations have been described based on associations between physical properties of bread and process parameters (Różyło, 2014b). In this paper, a further transformation of the second degree polynomial equation to the canonical form was proposed (Table 2). Such 


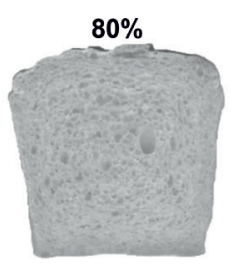

CC

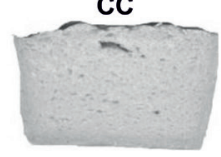

CF

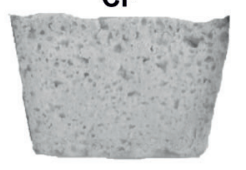

RF

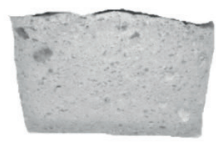

CRF

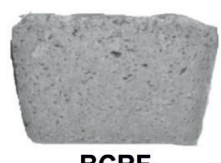

BCRF

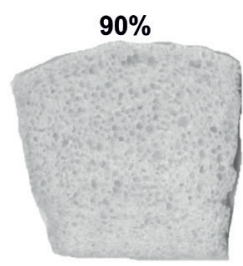

CC

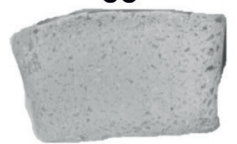

CF

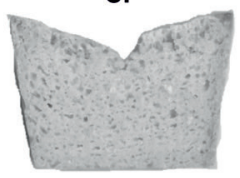

RF

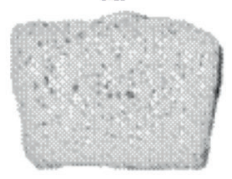

CRF

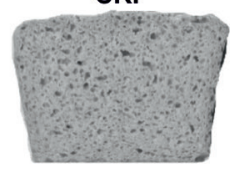

BCRF

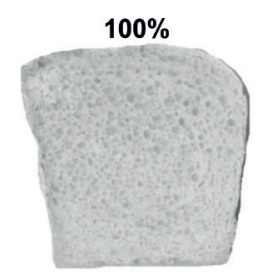

CC

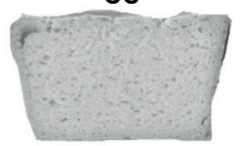

CF

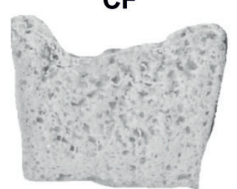

RF

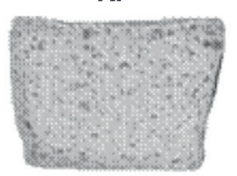

CRF

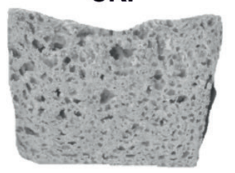

BCRF

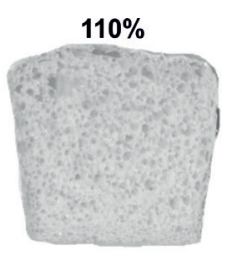

CC

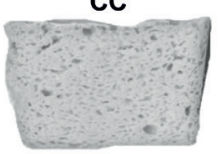

CF

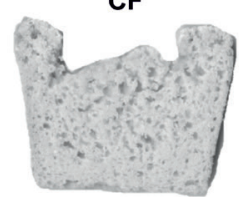

RF

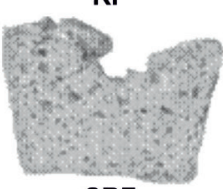

CRF

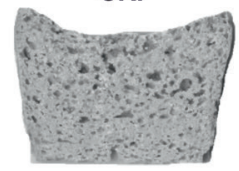

BCRF

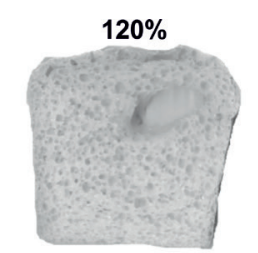

CC

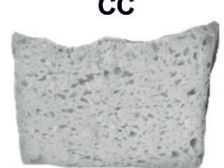

CF

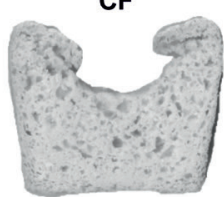

RF

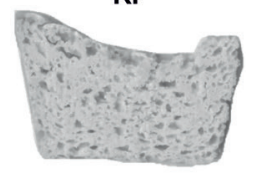

CRF

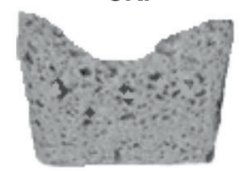

BCRF

Fig. 1. Overall appearance of gluten-free bread baked with increasing (80-120\%) amounts of water addition. CC, CF, RF, CRF, BCRF - bread formulations based on: commercial gluten-free bread concentrate (CC) as a control; corn flour (CF) (100\%); rice flour (RF) (100\%); corn and rice flour (CRF) (50:50\%), buckwheat, corn, and rice flour (BCRF) (30:35:35\%).

a transformation facilitates the readout of water addition quantities ( $p$-value) at the maximal predicted values of bread physical properties (q-value).

Bread volume is one of the most frequently determined parameter for bread quality evaluation (Kasprzak and Rzedzicki, 2010). In the case of wheat bread, the addition of gluten free ingredients to wheat flour negatively affects dough rheological properties and bread quality (Karaoglu, 2012).

Gluten-free bread volumes are shown in Fig. 2a, while Table 1 presents the regression equations describing the changes in the bread volume. Analysis of the results showed that the bread volume was significantly dependent both on the type of raw material and on the amount of water used in the recipe (Fig. 2a). Schoenlechner et al., (2010), who studied bread made with amaranth flour, noticed that water amounts in comparison with albumen and fat caused significant changes in bread volume. In the literature, there are no studies or descriptions of the qualitative changes of different types of natural gluten-free bread under the influence of increasing levels of water addition.

In other studies relating to gluten-free bread enriched with technological additives, significant changes in loaf volume under the influence of different levels of water addition have also been noticed (de la Hera et al., 2013; Hager and Arendt, 2013; Lazaridou et al., 2007; Schoenlechner et al., 2010). The changes were dependent on the type of the additive used (Lazaridou et al., 2007).

In our study bread made of corn flour required the largest amount of water addition; a great volume was achieved with a $120 \%$ water addition. According to our study, the volume of corn flour bread increased linearly (Table 1) with the addition of water to the dough.

With lower amounts of water addition ie 80 and 100\%, the corn bread was not well-risen and the crumb was dense and brittle. Schober et al. (2005) explained that, due to the lack of gluten, gluten-free dough is more fluid than wheat flour dough and close to batter in terms of viscosity. This system usually has to be handled in a way similar to cake batter rather than typical bread dough.

The rice bread volume was the highest at $90 \%$ of water addition; however, it should be noted that, with this additive, bread was already collapsed. Bread made of corn and rice reached its maximum volume $\left(178.7 \mathrm{~cm}^{3}\right)$ at $100 \%$ of water addition. The canonical equation (Table 2) reveals that the maximum volume of bread $\left(181 \mathrm{~cm}^{3}\right)$ can be obtained at $104.3 \%$ of water addition. Regardless of the different levels of water addition to dough, the highest volume was represented by bread produced from the ready-made gluten-free concentrate (the control bread). 
a
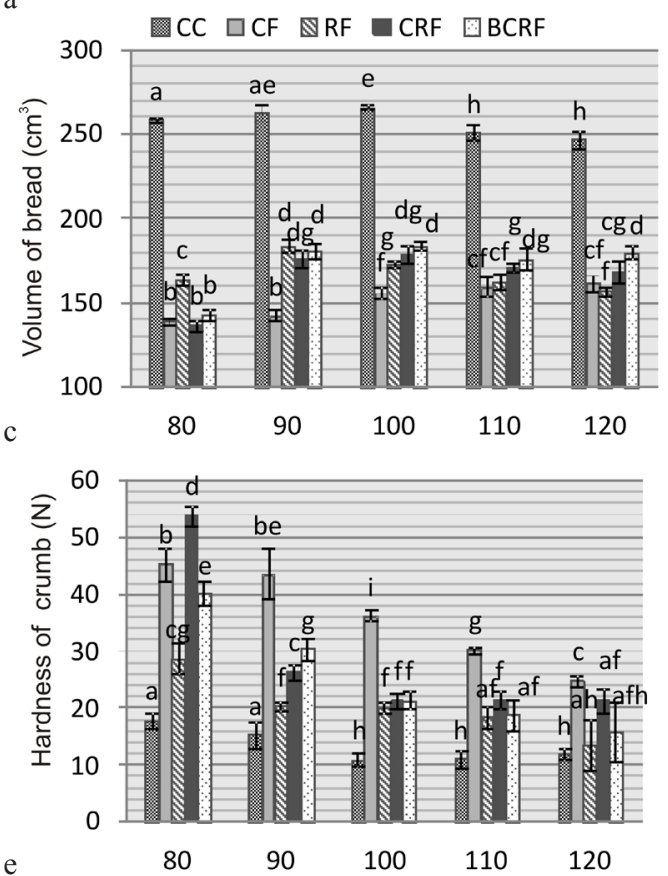

e

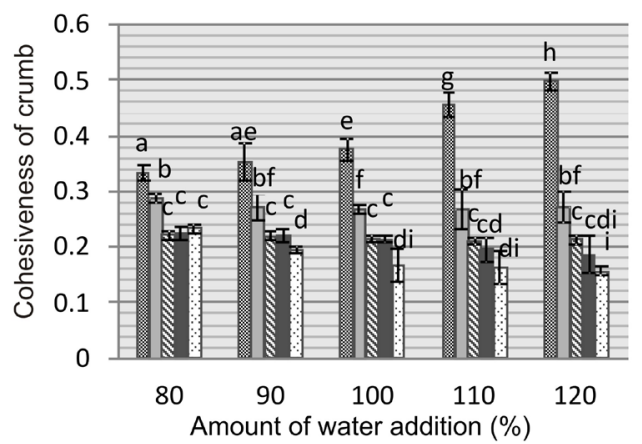

b
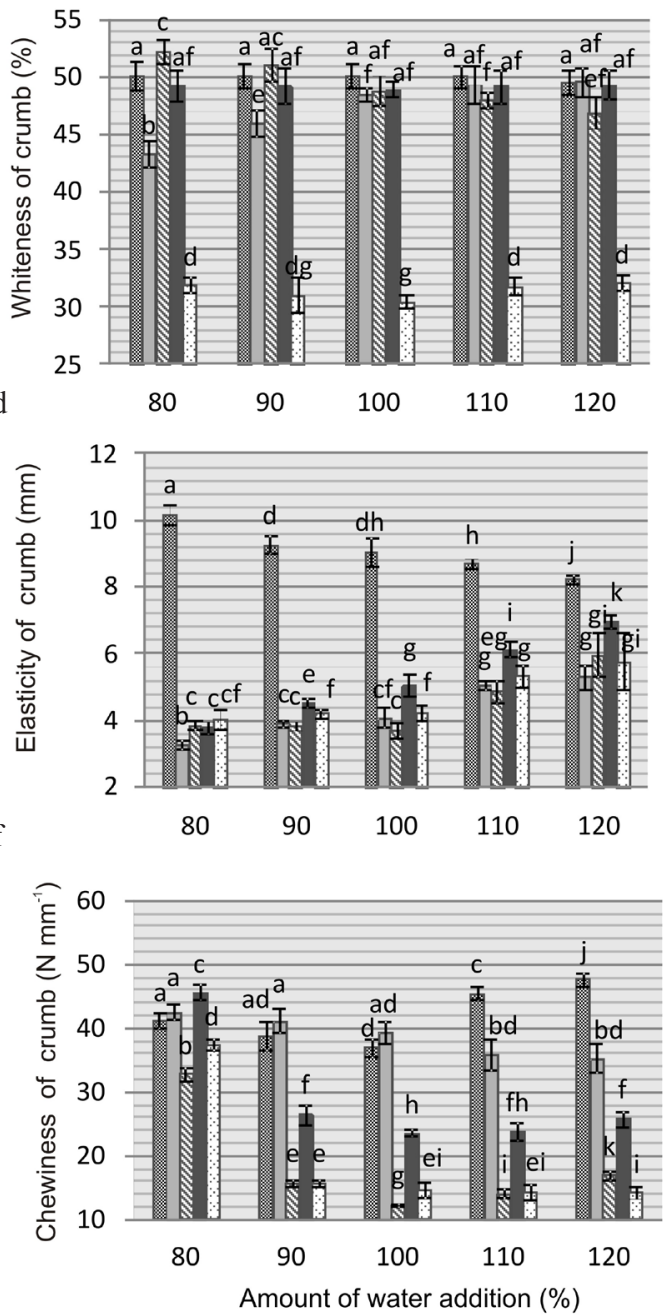

Fig. 2. Physical properties of gluten-free bread baked with different amounts of water addition: $a-$ volume of bread, $b-$ whiteness of crumb, $\mathrm{c}$ - hardness of crumb, $\mathrm{d}$ - elasticity of crumb, e - cohesiveness of crumb, $\mathrm{f}$ - chewiness of crumb. $\mathrm{a}, \mathrm{b}, \mathrm{c}, \mathrm{d}, \mathrm{e}, \mathrm{f}-\mathrm{columns}$ with different letter are significantly different $(\alpha<0.05)$. Explanations as in Fig. 1.

The control bread consisted of guar gum, pectin, and mono and diglyceride of fatty acids, which caused significant increases in the bread volume. Among natural gluten-free breads, the highest volume was represented by rice bread, and the lowest volume was observed for corn bread. According to Hager et al. (2012), rice bread was characterized by significantly higher specific volumes in comparison to corn bread.

Similarly to the volume, the porosity of the crumb (pore percentage area) was strongly influenced by the amount of water in the dough (Table 3). For all the investigated gluten-free bread loaves, increasing water addition in the range of 80 to $120 \%$ caused significant changes in the area occupied by the pores. An increase in the pore percentage area was observed.

The whiteness of gluten-free bread crumb baked with increasing amounts of water addition is presented in Fig. 2b. Significant differences in the brightness of bread crumb produced from different raw materials were reported. The highest brightness was obtained for the crumb of bread from rice flour, a little less brightness was reported for gluten-free bread from the concentrate, and the least brightness was noticed for the bread crumb made of buckwheat flour. These differences are explained by the colour of the raw materials: the rice flour was brightly coloured; the gluten-free concentrate consisting of starch was also characterized by a bright colour; the corn flour was yellow; and the wholegrain buckwheat flour was significantly darker in colour, due to the high proportion of seed coat. Similarly, in another study with increasing amounts of buckwheat flour in bread formulations, a decrease in crumb whiteness was noticed when compared with the control sample (corn and potato starch) (Wronkowska et al., 2013). Associations between crumb brightness and water content are shown in Table 1, and the canonical function is presented in Table 2. 
T a b I e 1. Regression equations describing the properties of different types of gluten-free bread crumb versus the amount of water addition

\begin{tabular}{|c|c|c|c|}
\hline Property of bread & Kind of gluten-free bread & Form of equation & $\mathrm{R}^{2}$ \\
\hline \multirow{5}{*}{ Volume of bread $\left(\mathrm{cm}^{3}\right)$} & $\mathrm{CC}$ & $f(x)=-0.0249 x^{2}+4.6182 x+48.699$ & 0.819 \\
\hline & $\mathrm{CF}$ & $f(x)=0.6142 x^{2}+90.025$ & 0.914 \\
\hline & $\mathrm{RF}$ & $f(x)=-0.0353 x^{2}+6.7003 x-142.25$ & 0.700 \\
\hline & $\mathrm{CRF}$ & $f(x)=-0.0678 x^{2}+14.147 x-556.93$ & 0.831 \\
\hline & BCRF & $f(x)=-0.0558 x^{2}+11.845 x-443.51$ & 0.810 \\
\hline \multirow{5}{*}{ Whiteness of crumb (\%) } & $\mathrm{CC}$ & $f(x)=-0.0008 x^{2}+0.1518 x+43.168$ & 0.906 \\
\hline & $\mathrm{CF}$ & $f(x)=-0.0048 x^{2}+1.1293 x-16.222$ & 0.996 \\
\hline & $\mathrm{RF}$ & $f(x)=-0.1377 x+63.123$ & 0.973 \\
\hline & $\mathrm{CRF}$ & $f(x)=0.0007 x^{2}-0.133 x+55.555$ & 0.772 \\
\hline & BCRF & $f(x)=0.003 x^{2}-0.5837 x+59.458$ & 0.728 \\
\hline \multirow{5}{*}{ Hardness of crumb (N) } & $\mathrm{CC}$ & $f(x)=0.008 x^{2}-1.766 x+108.09$ & 0.941 \\
\hline & $\mathrm{CF}$ & $f(x)=-0.5455 x+90.482$ & 0.975 \\
\hline & RF & $f(x)=-0.3184 x+51.934$ & 0.863 \\
\hline & $\mathrm{CRF}$ & $f f(x)=0.0423 x^{2}-9.1426 x+512.07$ & 0.924 \\
\hline & $\mathrm{BCRF}$ & $f(x)=-0.5998 x+85.193$ & 0.920 \\
\hline \multirow{5}{*}{ Elasticity of crumb (mm) } & $\mathrm{CC}$ & $f(x)=-0.0441 x+13.485$ & 0.945 \\
\hline & $\mathrm{CF}$ & $f(x)=0.0521 x-0.9045$ & 0.962 \\
\hline & $\mathrm{RF}$ & $f(x)=0.0523 x-0.8022$ & 0.736 \\
\hline & $\mathrm{CRF}$ & $f(x)=0.0794 x-2.6647$ & 0.989 \\
\hline & BCRF & $f(x)=0.0459 x+0.1133$ & 0.863 \\
\hline \multirow{5}{*}{ Cohesiveness of crumb } & $\mathrm{CC}$ & $f(x)=-0.0441 x+13.485$ & 0.945 \\
\hline & $\mathrm{CF}$ & $f(x)=0.00003 x^{2}-0.0067 x+0.6167$ & 0.945 \\
\hline & $\mathrm{RF}$ & $f(x)=-0.0003 x+0.2436$ & 0.813 \\
\hline & $\mathrm{CRF}$ & $f(x)=-0.001 x+0.3108$ & 0.939 \\
\hline & BCRF & $f f(x)=-0.0019 x+0.3715$ & 0.860 \\
\hline \multirow{5}{*}{ Chewiness of crumb $\left(\mathrm{N} \mathrm{mm}^{-1}\right)$} & $\mathrm{CC}$ & $f(x)=0.0139 x^{2}-2.5883 x+158.48$ & 0.823 \\
\hline & $\mathrm{CF}$ & $f(x)=-0.1972 x+58.429$ & 0.957 \\
\hline & $\mathrm{RF}$ & $f(x)=0.0322 x^{2}-6.7832 x+367.81$ & 0.941 \\
\hline & $\mathrm{CRF}$ & $f(x)=0.0325 x^{2}-6.9244 x+389.86$ & 0.933 \\
\hline & BCRF & $f(x)=0.0314 x^{2}-6.7567 x+374.58$ & 0.887 \\
\hline
\end{tabular}

Explanations as in Fig. 1. 
T a b l e 2. Canonical form of the equations describing the quality of different gluten-free breads versus the amount of water addition

\begin{tabular}{|c|c|c|c|c|}
\hline Property of bread & $\begin{array}{c}\text { Kind of gluten-free } \\
\text { bread }\end{array}$ & Canonical form of equation & $\mathrm{p}$ & $q$ \\
\hline \multirow{5}{*}{ Volume of bread $\left(\mathrm{cm}^{3}\right)$} & $\mathrm{CC}$ & $f(x)=-0.0249(x-92.73494)^{2}+262.8332$ & 92.73493976 & 262.8332 \\
\hline & $\mathrm{CF}$ & - & - & - \\
\hline & $\mathrm{RF}$ & $f(x)=-0.0353(x-94.9051)^{2}+175.6963$ & 94.90509915 & 175.6963 \\
\hline & CRF & $f(x)=-0.0678(x-104.3289)^{2}+181.0405$ & 104.3289086 & 181.0405 \\
\hline & BCRF & $f(x)=-0.0558(x-106.138)^{2}+185.0923$ & 106.1379928 & 185.0923 \\
\hline \multirow{5}{*}{ Whiteness of crumb (\%) } & $\mathrm{CC}$ & $f(x)=-0.0249(x-92.73494)^{2}+262.8332$ & 92.73493976 & 262.8332 \\
\hline & $\mathrm{CF}$ & $f(x)=-0.0091(x-134.033)^{2}+164.0719$ & 134.032967 & 164.0719 \\
\hline & RF & $f(x)=-0.0353(x-94.9051)^{2}+175.6963$ & 94.90509915 & 175.6963 \\
\hline & CRF & $f(x)=-0.0678(x-104.3289)^{2}+181.0405$ & 104.3289086 & 181.0405 \\
\hline & $\mathrm{BCRF}$ & $f(x)=-0.0558(x-106.138)^{2}+185.0923$ & 106.1379928 & 185.0923 \\
\hline \multirow{5}{*}{ Hardness of crumb (N) } & $\mathrm{CC}$ & $f(x)==0.008(x-110.375)^{2}+10.62888$ & 110.375 & 10.62888 \\
\hline & $\mathrm{CF}$ & - & - & - \\
\hline & RF & - & - & - \\
\hline & CRF & $f(x)==0.0423(x-108.0686)^{2}+18.0562$ & 108.0686 & 18.0562 \\
\hline & $\mathrm{BCRF}$ & - & - & - \\
\hline \multirow{5}{*}{ Cohesiveness of crumb } & $\mathrm{CC}$ & - & - & - \\
\hline & $\mathrm{CF}$ & $f(x)=0.00003(x-11.6667)^{2}+0.242617$ & 111.6667 & 0.242617 \\
\hline & RF & - & - & - \\
\hline & $\mathrm{CRF}$ & - & - & - \\
\hline & BCRF & - & - & - \\
\hline \multirow{5}{*}{ Chewiness of crumb $\left(\mathrm{N} \mathrm{mm}^{-1}\right)$} & $\mathrm{CC}$ & $f(x)=0.0139(x-93.10432)^{2}+7.98905$ & 93.10432 & 37.98905 \\
\hline & $\mathrm{CF}$ & - & - & - \\
\hline & $\mathrm{RF}$ & $f(x)=0.0322(x-105.3292)^{2}+10.57551$ & 105.3292 & 10.57551 \\
\hline & $\mathrm{CRF}$ & $f(x)=0.0325(x-106.5292)^{2}+21.0345$ & 106.5292 & 21.0345 \\
\hline & BCRF & $f(x)=0.0314(x-107.5908)^{2}+11.10074$ & 107.5908 & 11.10074 \\
\hline
\end{tabular}

Explanations as in Fig. 1.

The hardness of different types of gluten-free bread the use of substances (guar gum, pectin, and mono and made from dough with different water concentrations in the recipe is shown in Fig. 2c, and regression equations describing the hardness of the crumb are provided in Table 1, while the canonical function equations are shown in Table 2. The control bread from the gluten-free concentrate was characterized by the lowest crumb hardness caused by diglyceride of fatty acids) aimed at improving the quality of bread. Among the gluten-free breads without any improvers, the lowest hardness was described for bread made of RF, and the highest for CF bread. Similar relationships were obtained in the study conducted by Hager et al. 
T a b l e 3. Staling degree, value of heterogeneity index, and qualitative description of crumb structure of gluten free bread baked with different amounts of water addition

\begin{tabular}{|c|c|c|c|c|c|}
\hline $\begin{array}{c}\text { Kind of gluten-free } \\
\text { bread }\end{array}$ & $\begin{array}{l}\text { Amount of water } \\
\text { addition }(\%)\end{array}$ & $\begin{array}{c}\text { Pores percentage } \\
\text { area }(\%)\end{array}$ & $\begin{array}{l}\text { Staling degree of } \\
\text { bread BSd }(\%)^{*}\end{array}$ & $\begin{array}{c}\text { Value of index of } \\
\text { heterogeneity }(\%)^{*}\end{array}$ & $\begin{array}{c}\text { Qualitative } \\
\text { description of bread } \\
\text { crumb structure* }\end{array}$ \\
\hline \multirow{5}{*}{$\mathrm{CC}$} & 80 & $18.54 \pm 1.10 \mathrm{a}$ & $16.76 \pm 2.87 \mathrm{a}$ & $25.37 \pm 4.32 \mathrm{a}$ & $\mathrm{HBC}$ \\
\hline & 90 & $19.32 \pm 1.03 \mathrm{a}$ & $24.88 \pm 1.44 b$ & $24.79 \pm 3.21 \mathrm{a}$ & $\mathrm{HBC}$ \\
\hline & 100 & $22.30 \pm 0.98 b$ & $72.95 \pm 4.06 \mathrm{c}$ & $20.71 \pm 2.44 \mathrm{a}$ & $\mathrm{HBC}$ \\
\hline & 110 & $28.50 \pm 1.55 \mathrm{cj}$ & $70.59 \pm 5.43 c$ & $25.90 \pm 3.19 \mathrm{a}$ & $\mathrm{HBC}$ \\
\hline & 120 & $35.76 \pm 1.32 \mathrm{~d}$ & $67.49 \pm 7.23 c$ & $47.46 \pm 6.31 b$ & MHBC \\
\hline \multirow{5}{*}{$\mathrm{CF}$} & 80 & $5.54 \pm 0.39 \mathrm{e}$ & $78.39 \pm 2.24 \mathrm{~d}$ & $19.79 \pm 3.02 \mathrm{a}$ & $\mathrm{HBC}$ \\
\hline & 90 & $6.96 \pm 0.43 \mathrm{f}$ & $27.77 \pm 1.01 \mathrm{e}$ & $20.00 \pm 2.14 \mathrm{a}$ & $\mathrm{HBC}$ \\
\hline & 100 & $8.54 \pm 0.72 \mathrm{~g}$ & $22.15 \pm 3.15 \mathrm{ab}$ & $15.55 \pm 0.42 \mathrm{c}$ & $\mathrm{HBC}$ \\
\hline & 110 & $11.32 \pm 1.15 \mathrm{~h}$ & $13.01 \pm 0.52 \mathrm{f}$ & $14.00 \pm 1.87 \mathrm{c}$ & $\mathrm{HBC}$ \\
\hline & 120 & $12.54 \pm 1.09 \mathrm{~h}$ & $3.96 \pm 0.11 \mathrm{~g}$ & $13.99 \pm 2.01 \mathrm{c}$ & $\mathrm{HBC}$ \\
\hline \multirow{5}{*}{$\mathrm{RF}$} & 80 & $14.67 \pm 0.72 \mathrm{hi}$ & $85.82 \pm 8.12 \mathrm{~d}$ & $19.50 \pm 5.24 \mathrm{ac}$ & $\mathrm{HBC}$ \\
\hline & 90 & $15.88 \pm 0.85 \mathrm{i}$ & $79.17 \pm 2.43 \mathrm{~d}$ & $31.03 \pm 1.02 \mathrm{~d}$ & MHBC \\
\hline & 100 & $20.45 \pm 1.04 \mathrm{ab}$ & $66.50 \pm 5.54 \mathrm{c}$ & $33.65 \pm 2.34 \mathrm{~d}$ & MHBC \\
\hline & 110 & $25.58 \pm 1.42 j$ & $61.74 \pm 4.87 \mathrm{c}$ & $39.00 \pm 7.43 \mathrm{bd}$ & MHBC \\
\hline & 120 & $28.92 \pm 1.33 \mathrm{c}$ & $61.47 \pm 5.23 c$ & $43.69 \pm 3.78 b$ & MHBC \\
\hline \multirow{5}{*}{$\mathrm{CRF}$} & 80 & $6.43 \pm 0.31 \mathrm{f}$ & $68.96 \pm 3.13 c$ & $15.02 \pm 0.34 \mathrm{c}$ & $\mathrm{HBC}$ \\
\hline & 90 & $11.56 \pm 0.57 \mathrm{~h}$ & $55.06 \pm 1.01 \mathrm{~h}$ & $12.78 \pm 2.13 \mathrm{ce}$ & $\mathrm{HBC}$ \\
\hline & 100 & $15.82 \pm 0.83 \mathrm{i}$ & $46.90 \pm 8.03 \mathrm{~h}$ & $10.18 \pm 1.01 \mathrm{e}$ & HBC \\
\hline & 110 & $24.47 \pm 1.28 \mathrm{bj}$ & $23.58 \pm 1.37 \mathrm{~b}$ & $20.00 \pm 5.39 \mathrm{ac}$ & $\mathrm{HBC}$ \\
\hline & 120 & $27.93 \pm 1.31 \mathrm{cj}$ & $9.55 \pm 3.21 \mathrm{f}$ & $29.88 \pm 1.56 \mathrm{~d}$ & $\mathrm{HBC}$ \\
\hline \multirow{5}{*}{ BCRF } & 80 & $7.23 \pm 0.45 f$ & $66.82 \pm 2.32 \mathrm{c}$ & $17.99 \pm 5.45 \mathrm{ac}$ & $\mathrm{HBC}$ \\
\hline & 90 & $18.45 \pm 1.02 \mathrm{a}$ & $47.50 \pm 7.02 \mathrm{~h}$ & $15.87 \pm 0.22 \mathrm{c}$ & $\mathrm{HBC}$ \\
\hline & 100 & $26.33 \pm 1.43 \mathrm{cj}$ & $10.48 \pm 2.42 \mathrm{f}$ & $12.63 \pm 3.54 \mathrm{ce}$ & $\mathrm{HBC}$ \\
\hline & 110 & $29.54 \pm 1.39 c$ & $8.94 \pm 3.78 \mathrm{f}$ & $18.69 \pm 3.20 \mathrm{ac}$ & $\mathrm{HBC}$ \\
\hline & 120 & $31.34 \pm 1.47 \mathrm{c}$ & $7.82 \pm 4.86 \mathrm{fg}$ & $27.66 \pm 2.51 \mathrm{ad}$ & $\mathrm{HBC}$ \\
\hline
\end{tabular}

* Mean \pm standard deviation. Means with different letters within the same row are significantly different $(\alpha<0.05)$. HBC - homogeneous bread crumb, MHBC - medium homogeneous bread crumb. 
(2012), where these authors noticed that bread from rice flour had significantly lower bread crumb hardness than that from maize flour.

The hardness of the bread (Fig. 2c) made of CF and RF as well as of BCRF significantly decreased in a linear manner with increases in water additions in the range from 80 to $120 \%$. Schoenlechner et al. (2010), who studied bread with amaranth, also noticed significant changes in crumb hardness under the influence of different levels of water addition. In our study, the hardness of the gluten-free bread made of CRF decreased to a certain point, then an increase in hardness was observed. The association is shown as a second degree polynomial (Table 1), which was transformed into the canonical equation (Table 2). The canonical equation reveals that the lowest hardness will be obtained witha water addition at the level of $108 \%$.

The elasticity of the bread crumb (Fig. 2d) was also different. The gluten-free bread from the concentrate was characterized by very good elasticity. The lowest elasticity was observed for cornbread, while significantly higher elasticity was reported for breads made of mixtures. With the increase in the water addition to the dough, the elasticity of the control bread crumb decreased, while this feature increased for the natural gluten-free breads. The associations are presented in a linear form in Table 3. Studies conducted by Schoenlechner et al. (2010) did not comprise equations describing the changes, but the authors also observed significant changes in the relative elasticity of gluten-free bread with amaranth flour with increasing amounts of water content.

Crumb cohesiveness (Fig. 2e) also differed between the studied types of gluten-free bread. The cohesiveness of the control bread (CC) increased with an increasing addition of water content to the recipe. The cohesiveness of bread made of $\mathrm{CF}$ decreased and then increased (quadratic equation - Table 3) and the cohesiveness of other gluten-free breads was characterized by a slight decrease. Based on data shown for hardness and cohesiveness (the two main parameters for crumb texture), it seems that $100-110 \%$ water gave the most interesting results for texture although this may be a little high for rice bread.

A high level of chewiness (Fig. 1f) was observed for bread made of the commercial gluten-free concentrate (CC) and CF. Chewiness is characterized as the ratio of hardness, elasticity, and cohesion. Cornbread was found to have the highest hardness and bread made of the gluten-free concentrate was found to be the most flexible, which influenced the achievement of high values in terms of crumb chewiness. Changes in the chewiness of the control bread (Table 1) were presented as a second degree polynomial, and the canonical form of equation (Table 2) reveals that the lowest chewiness of the crumb can be achieved with the addition of water at a level of $93 \%$.
The chewiness of the crumb from the CF bread decreased with the increasing addition of water to the recipe (linear equation - Table 1). Associations between crumb chewiness and the remaining gluten-free breads (RF, CRF, $\mathrm{BCRF}$ ) are presented as quadratic functions (Table 3); at the beginning, a decrease followed by a further increase in chewiness was observed. Canonical forms (Table 2) show that the lowest chewiness is observed for bread made of $\mathrm{RF}, \mathrm{CRF}$, as well as buckwheat, BCRF with the addition of water at about 105,106 , and $107 \%$.

The degree of staling of the breads in the study is shown in Table 3. Comparison of different gluten-free breads revealed that, at the optimum addition of water, the lowest degree of staling was observed for the bread made of CF; however, considering that its hardness meant that it was not accepted by consumers, the highest score was obtained by the bread made with BCRF. In comparison, CC (the only bread containing hydrocolloids and emulsifiers) had a much softer, lighter, and more porous structure; its porosity increased significantly further by increasing the addition of water. A low degree of staling of the $\mathrm{CC}$ bread was achieved at the optimum addition of water of $80-90 \%$ (sufficiently hydrated starch), while increasing the addition of water in the range of $100-120 \%$ may contribute to the free water (not bonded with starch) content in the crumb. With the $80 \%$ share of water in the recipe, the hardness of the CC bread after 1 day of storage was $17.74 \mathrm{~N}$ and after 3 days of storage only $20.71 \mathrm{~N}$ (staling rate of $16.76 \%$ ). However, in the case of $120 \%$ of the water in the recipe, the hardness of the bread crumb on the first day was equal to $11.79 \mathrm{~N}$ and after 3 days increased to $19.76 \mathrm{~N}$ (staling rate of 67.495). Such a large change in the case of bread stored in whole loaves could be caused by intense migration of water from the middle crumb to the crust. An opposite trend was observed for bread without improving additives. For example, corn bread $\mathrm{CF}$ with a yield of $80 \%$ was dense with high crumb hardness after 1 day $(45.22 \mathrm{~N})$ and after 3 days $(80.66 \mathrm{~N})$. Addition of water in this case was insufficient, which could manifest insufficiently bonded starch and this may have contributed to the intensification of retrogradation during storage. With a high addition of water (120\%), the lowest hardness after 1 day $(24.65 \mathrm{~N})$ and after 3 days $(25.62 \mathrm{~N})$ was observed. Sufficiently hydrated starch was less prone to staling. It should be emphasized that changes in bread staling under the influence of water addition may vary depending on the degree of swelling of the starch, the starch grain size (due to different recipe composition), and the intensity of water migration in the crumb with different hardness and porosity. The addition of enhancers could also affect the nature of the changes. According to other authors, bread staling is a complex phenomenon in which multiple mechanisms operate. Gray and Bemiller (2003) found that 

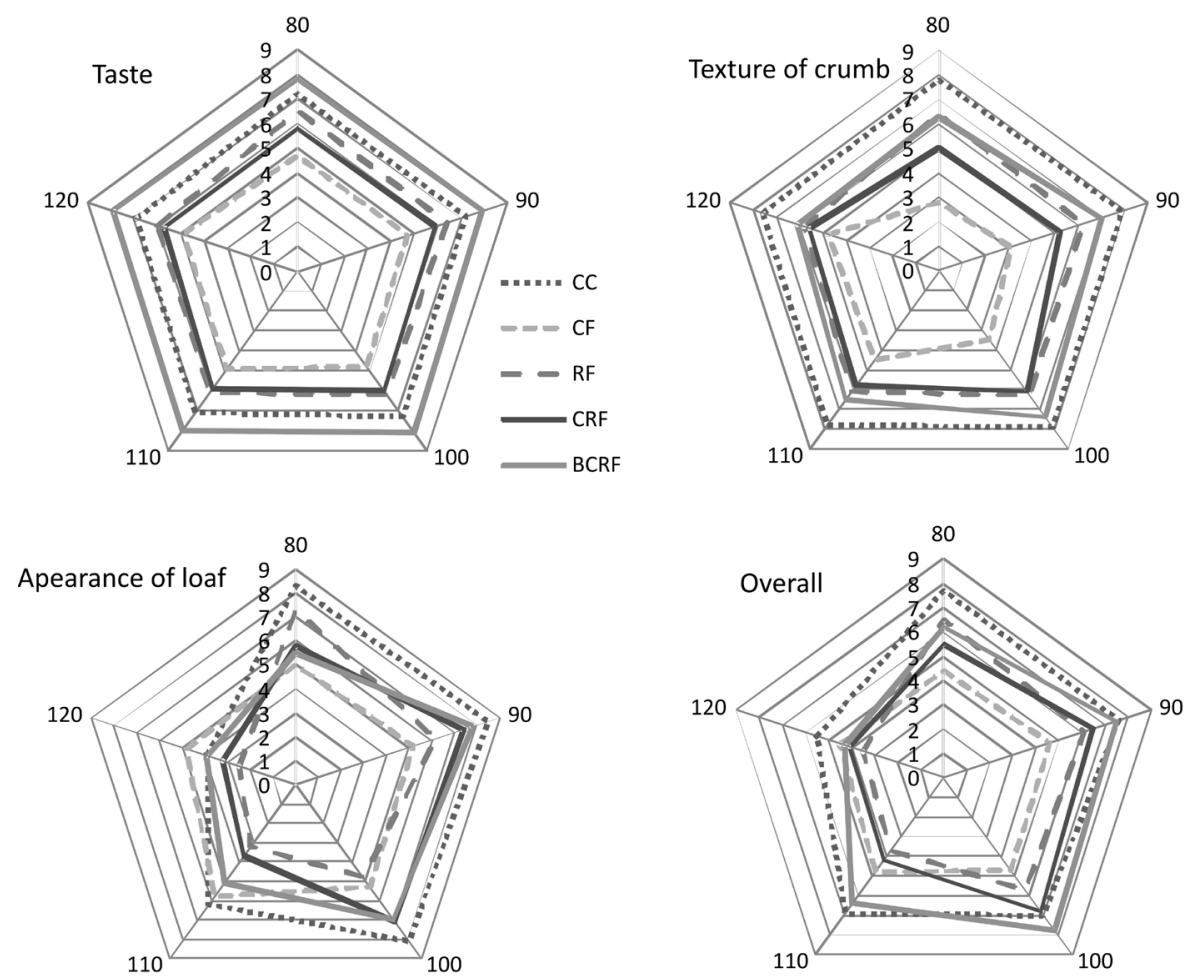

Fig. 3. Sensory evaluation of gluten-free bread prepared using different amounts of water addition.

amylopectin retrogradation was part of the staling process. He and Hoseney (1990) demonstrated that changes in moisture content were the other factors that could relate to staling of bread.

Unlike maize and rice, buckwheat contains more soluble proteins that affect its dough and crumb structure (Hong and Kim, 2006). Other authors (Wronkowska et al., 2013) have observed that increased amounts of buckwheat flour in gluten-free bread formulations caused a decrease in crumb hardness during storage. This was in agreement with the decrease in starch gelatinization enthalpy experienced with increased amounts of buckwheat flour in a gluten-free formula in comparison with the control sample. Buckwheat flour could be incorporated into a gluten-free formula and have a positive influence on bread texture and also delay its staling.

The heterogeneity index value of bread crumb (Table 5) enabled the classification of the majority of breads as part of a homogeneous group due to the fact that the gluten-free breads were insufficiently raised and were characterized by compensated porosity. Bread made of RF with increased water addition tended to collapse, which resulted in a significant deterioration in crumb evaluation.

In our study, the sensory evaluation (Fig. 3) showed that the lowest sensitivity to water addition changes was presented by the bread made of the gluten-free concentrate. The bread made of corn flour required the largest amount of water addition; good quality was achieved with a $120 \%$ water addition. With lower amounts of water addition ie 80 and $100 \%$, corn bread was not well-raised and the crumb was dense and brittle. Bread made of rice flour was characterized by the best quality scores at the lowest amount of water addition $(80 \%)$. Increased amounts of water addition were implicated in obtaining irregularly shaped bread with collapsed surfaces; however, the bread crumb was soft. Breads made of corn and rice flour, as well as corn, rice, and buckwheat flour, have been reported to behave similarly. With a water addition of $90 \%$, these bread types maintained the best quality. Bread made with the addition of BCRF obtained better taste evaluations, which influenced its overall assessment.

\section{CONCLUSIONS}

1. Bread made of corn flour required the largest amount of water addition (120\%); however, bread made of rice flour was characterized by better quality at the lowest amount of water addition (80\%), and breads made of corn and rice flour as well as of buckwheat, corn, and rice flour were characterized by the best quality at $90 \%$ of water addition.

2. Among gluten-free breads without any improvers, the highest volume was represented by rice bread, and the lowest volume was observed for corn bread. Increasing water 
addition in the range of 80 to $120 \%$ caused significant changes in the area occupied by pores. An increase in the pore percentage area was observed.

3. The control bread from the gluten-free concentrate was characterized by the lowest crumb hardness caused by the use of substances (guar gum, pectin, and mono and diglyceride of fatty acids) aimed at improving the quality of bread. Among gluten-free breads without any improvers, the lowest hardness was described for bread made of rice flour, and the highest for corn flour bread. Comparison of different gluten-free breads revealed that, at the optimum addition of water, the lowest degree of staling was observed for bread made of corn flour; however, considering that its hardness meant that it was not accepted by consumers, the highest score was obtained by bread made with buckwheat flour.

4. Changes in the quality of bread were described as a second degree polynomial regression equation or linear regression. If a quadratic equation was considered, its conversion into a canonical form was proposed, facilitating a quick readout of the water addition amount essential to obtain the desired physical properties.

5. Sensory evaluation showed that bread made with the addition of buckwheat flour obtained better taste evaluations, which influenced its overall assessment.

\section{REFERENCES}

De la Hera E., Talegón M., Caballero P., and Gómez M., 2013. Influence of maize flour particle size on gluten-free breadmaking. J. Sci. Food Agric., 93, 924-932.

Gambuś H., Sikora M., and Ziobro R., 2007. The effect of composition of hydrocolloids on properties of gluten-free bread. Acta Sci. Pol.-Technol. Alimentaria, 63, 61-74.

Gámbaro A., Giménez A., Ares G., and Gilardi V., 2006. Influence of enzymes on the texture of brown pan bread. J. Texture Studies, 37, 300-314.

Gómez M., Talegón M., and De La Hera E., 2013. Influence of mixing on quality of gluten-free bread. J. Food Quality, 36, 139-145.

Gray J.A. and Bemiller J.N., 2003. Bread staling: Molecular basis and control. CRFSFS: Comprehensive Reviews in Food Sci. Food Safety, 2, 1-21.

Hager A.S. and Arendt E., 2013. Influence of hydroxypropylmethylcellulose (HPMC), xanthan gum and their combination on loaf specific volume, crumb hardness and crumb grain characteristics of gluten-free breads based on rice, maize, teff and buckwheat. Food Hydrocolloids, 32, 195-203.

Hager A.S., Wolter A., Czerny M., Bez, J., Zannini E., Arendt E.K., and Czerny M., 2012. Investigation of product quality, sensory profile and ultrastructure of breads made from a range of commercial gluten-free flours compared to their wheat counterparts. European Food Res. Technol., 235, 333-344.

He H. and Hoseney R.C., 1990. Changes in bread firmness and moisture during long-term storage. Cereal Chem., 67, 603-605.
Hong C.S. and Kim K.E., 2006. Buckwheat allergy. In: Nutraceutical Proteins and Peptides in Health and Disease. (Eds Y. Mine, S. Fereidoon). Taylor Francis, Boca Raton, FL, USA.

ISO 20483, 2006. Cereals and pulses - determination of the nitrogen content and calculation of the crude protein content -Kjeldahl method).

ISO 2171, 2007. Cereals, pulses and by-products - determination of ash yield by incineration.

ISO 11085, 2008. Cereals, cereals-based products and animal feeding stuffs - determination of crude fat and total fat content by the randall extraction method.

Jakubczyk T. and Haber T., 1983. Analysis of cereals and cereals products. Warsaw University of Life Sciences Press, Warsaw, Poland.

Karaoğlu M.M., 2012. Effect of Cephalaria syriaca addition on rheological properties of composite flour. Int. Agrophys., 26, 387-393.

Kasprzak M. and Rzedzicki Z., 2010. Effect of pea seed coat admixture on physical properties and chemical composition of bread. Int. Agrophys., 24, 149-156.

Lazaridou A., Duta D., Papageorgiou M., Belc N., and Biliaderis C.G., 2007. Effects of hydrocolloids on dough rheology and bread quality parameters in gluten-free formulations. J. Food Eng., 79, 1033-1047.

Lim H.S., Park S.H., Ghafoor K., Hwang S.Y., and Park J., 2011. Quality and antioxidant property of bread containing turmeric (Curcuma longa L.) cultivated in South Korea. Food Chem., 112, 1577-1582.

Mariotti M., Pagani A., and Lucisano M., 2013. The role of buckwheat and HPMC on the breadmaking properties of some commercial gluten-free bread mixtures. Food Hydrocolloids, 30, 393-400.

Matos M.E. and Rosell C.M., 2012. Relationship between instrumental parameters and sensory characteristics in gluten-free breads. European Food Res. Technol., 235(1), 107-117.

Mccarthy D.F., Gallagher E., Gormley T.R., Schober T.J., and Arendt E.K., 2005. Application of response surface methodology in the development of gluten-free bread. Cereal Chem., 82, 609-615.

Nishita D.D., Roberts R.L., and Bean M.M., 1975. Development of a yeast-leavened rice-bread formula. Cereal Chem., 535, 626-635.

Różyło R., 2013. Determining the heterogeneity of wheat breadcrumb texture baked using two different methods: New application. Int. J. Food Properties, 161, 154-167.

Różyło R., 2014a. New potential in using millet-based yeast fermented leaven for composite wheat bread preparation. J. Food Nutr. Res., 53(3), 240-250.

Różyło R., 2014b. Effect of process modifications in two cycles of dough mixing on physical properties of wheat bread baked from weak flour. Food Bioprocess Technol., 7, 774-783.

Różyło R., Dziki D., and Laskowski J., 2014. Changes in the physical and the sensorial properties of wheat bread caused by interruption and slowing of the fermentation of yeastbased leaven. J. Cereal Sci., 59, 88-94.

Różyło R., Rudy S., Krzykowski A., Dziki D., Gawlik-Dziki U., Różyło K., and Skonecki S., 2015a. Effect of adding fresh and freeze-dried buckwheat sourdough on gluten-free bread quality. Int. J. Food Sci. Technol., 50, 313-322. 
Różyło R., Rudy S., Krzykowski A., and Dziki D., 2015b. Novel application of freeze-dried amaranth sourdough in gluten-free bread production. J. Food Process Eng., 38, 135-143.

Sabanis D. and Tzia C., 2011. Effect of hydrocolloids on selected properties of gluten-free dough and bread. Food Sci. Technol. Int., 174, 279-291.

Sakac M., Torbica A., Sedej I., and Hadnadev M., 2011. Influence of breadmaking on antioxidant capacity of gluten free breads based on rice and buckwheat flours. Food Res. Int. J., 449, 2806-2813.

Schober T.J., Messerschmidt M., Bean S.R., Park S-H., and Arendt E.K., 2005. Gluten-free bread from sorghum: Quality differences among hybrids. Cereal Chem., 824, 394-404.

Schoenlechner R., Mandala I., Kiskini A., Kostaropoulos A., and Berghofer E., 2010. Effect of water, albumen and fat on the quality of gluten-free bread containing amaranth. Int. J. Food Sci. Technol., 454, 661-669.

Sciarini L.S., Perez G.T., Lamballerie M., De Leon A.E., and Ribotta P.D., 2012. Partial-baking process on gluten-free bread: impact of hydrocolloid addition. Food Bioprocess Technol., 55, 1724-1732.

Wronkowska M., Haros M., and Soral-Śmietana M., 2013. Effect of starch Substitution by buckwheat flour on glutenfree bread quality. Food Bioprocess Technol., 6, 1820-1827.

Wronkowska M. and Soral-Śmietana M., 2008. Buckwheat flour - a valuable component of gluten-free formulations. Polish J. Food Nutrition Sci., 581, 59-63.

Ziobro R., Korus J., Juszczak L., and Witczak T., 2013. Influence of inulin on physical characteristics and staling rate of gluten-free bread. J. Food Eng., 116, 21-27. 